
$\$$ Research Square
Preprints are preliminary reports that have not undergone peer review.
They should not be considered conclusive, used to inform clinical practice,
or referenced by the media as validated information.

\title{
The Efficacy and Acceptability of Exposure Therapy for the Treatment of Post- Traumatic Stress Disorder in Children and Adolescents: A Systematic Review and Meta-Analysis
}

\author{
Haomiao Li \\ Chongqing medical university \\ Tengyue Huang \\ Chongqing medical university \\ Shiyu Tan \\ Chongqing medical university \\ Siyu Xie \\ Chongqing medical university \\ Qisheng Cheng \\ Chongqing medical university \\ Yajie Xiang \\ The First Affiliated Hospital of Chongqing Medical University \\ Xinyu Zhou ( $\nabla$ zhouxinyu@cqmu.edu.cn) \\ The First Affiliated Hospital of Chongqing Medical University
}

Research Article

Keywords: Exposure therapy, Post-traumatic stress disorder, Children, Adolescents, Meta-analysis

Posted Date: October 14th, 2021

DOI: https://doi.org/10.21203/rs.3.rs-745685/v1

License: @ (i) This work is licensed under a Creative Commons Attribution 4.0 International License. Read Full License 


\section{Abstract}

\section{Background}

Posttraumatic stress disorder (PTSD) is common among children and adolescents who have experienced traumatic events. Exposure therapy (ET) has been shown to be effective in treating PTSD in adults. However, it remains uncertain in children and adolescents.

\section{Aims}

To evaluate the efficacy and acceptability of ET in children and adolescents with PTSD.

\section{Method}

We searched PubMed, EMBASE, Cochrane, Web of Science, PsycINFO, CINAHL, ProQuest, LILACS, international trial registries, and others for randomised controlled trials (RCTs) assessed ET in children and adolescents (aged $\leq 18$ years) with PTSD up to August 31, 2020. The primary outcomes were efficacy (the endpoint score from PTSD symptom severity rating scales) and acceptability (all-cause discontinuation), secondary outcomes included efficacy at followup (score from PTSD scales at the longest point of follow-up), depressive symptoms (end-point score on depressive symptom severity rating scales) and quality of life/social functioning (end-point score on quality of life/social functioning rating scales). This study was registered with PROSPERO (CRD42020150859).

\section{Result}

A total of six RCTs including 278 patients assessed ET. The results showed that ET was statistically more efficacious than control groups (standardized mean differences [SMD]: $-0.47,95 \%$ confidence interval [Cl]: -0.91 to -0.03). In subgroup analysis, exposure therapy was more efficacious for patients with single type of trauma (SMD: $-1.04,95 \% \mathrm{Cl}:-1.43$ to -0.65$)$, and the intervention using prolonged exposure therapy (PE) (SMD: $-1.04,95 \% \mathrm{Cl}:-1.43$ to -0.65$)$ was superior. Results for secondary outcomes of efficacy at follow-up (SMD: $-0.64,95 \% \mathrm{Cl}:-1.17$ to -0.10$)$ and depressive symptoms (SMD: -0.58 , $95 \% \mathrm{Cl}$ : -0.93 to -0.22 ) were similar to the findings for efficacy outcome. No statistically significant effects for acceptability and quality of life/social functioning were found.

\section{Conclusion}

ET showed superiority in efficacy at post-treatment/follow-up and depressive symptoms improvement in children and adolescents with PTSD. Patients with single type of trauma may benefit more from ET. Moreover, PE could be a better choice.

\section{Background}

Post-traumatic stress disorder (PTSD) is the most common and typical continuous severe psychological disorder in individuals after exposure to an unusual threatening or catastrophic event ${ }^{1-4}$. Children who experience traumatic events may develop PTSD with higher rates than adults ${ }^{5,6}$. It is reported that the overall rate of PTSD in trauma-exposed children and adolescents was $15.9 \%^{7}$. If PTSD is not treated, it may lead to additional psychiatric disorders such as depression, anxiety disorders, with functional impairment during both childhood and adulthood ${ }^{8}$. In many cases, PTSD can turn into a chronic disease, leading to considerable disease burdens and social and occupational disorders, huge economic and social costs and increased suicide risk ${ }^{9,10}$.

The psychotherapy is recommended as the initial treatment of PTSD in children and adolescents by several clinical guidelines ${ }^{11-14}$. Some believe that in order to adequately process traumatic memories and ultimately eliminate fear, memories must be activated and safety ingredients implanted ${ }^{15}$. Exposure therapy (ET) for traumatic memories, for the purpose of information including trauma situation and related emotions, thoughts and behaviors. ET has demonstrated its efficacy in the treatment of phobias, anxiety and PTSD in adults ${ }^{16}$. There are many kinds of exposure therapy available now, including prolonged exposure (PE), narrative exposure therapy (NET), kid narrative exposure therapy (KIDNET), etc. PE is a specific exposure-based type of cognitive behavior treatment (CBT) for PTSD, and it is accepted as a gold standard ${ }^{17}$, by safe confrontation with thoughts, memories, places, activities and people that have been avoided since a traumatic event occurred ${ }^{18}$. Narrative Exposure Therapy is a manualized, individual, short-term intervention program for the treatment of PTSD, based on $\mathrm{CBT}$ principles ${ }^{19}$. NET is adapted for the use with traumatized children and adolescents in a version called KIDNET $^{20}$.

However, the gradual promotion of PTSD exposure therapy has caused some controversies in the treatment of PTSD in children and adolescents, which was mainly related to ethical aspects and security risks ${ }^{21}$. Some studies reported that exposure therapy recalled the traumatic memory of children and adolescents, it suffered a high drop-out rate because of too low or too high patient engagement in treatment ${ }^{22,23}$, and evidence from sophisticated studies in clinical settings among children was limited ${ }^{24}$. Therefore, we performed a meta-analysis to systematically evaluate the efficacy and acceptability of exposure therapy in the treatment of PTSD in children and adolescents.

\section{Method}

The protocol of this meta-analysis has been registered in the PROSPERO database (CRD42020150859). The data that support the findings of this study are openly available in Mendeley at http://doi.org/10.17632/d6m4xhwtyw.3. We defined the main structured research question describing the Population, Intervention, Comparison, Outcome, and Study design (PICOS) in accordance with the recommendations by the Preferred Reporting Items for Systematic Reviews and Meta-analysis (PRISMA) groups ${ }^{25}$. 


\section{Search Strategy And Selection Criteria}

We searched PubMed, EMBASE, Cochrane, Web of Science, PsycINFO, CINAHL, ProQuest Dissertations, LILACS, international trials registers (such as World Health Organization trials portal, ClinicalTrials. gov and Australian New Zealand Clinical Trials Registry) including published and unpublished trials, from the date of database inception to August 31, 2020. We put no restrictions on language. We searched with different combinations of the following key words: Condition $=$ (posttrauma* OR post-trauma* OR post trauma* OR trauma* OR PTSD OR acute stress disorder* OR peritrauma* OR peri-trauma* OR avoidant disorder* OR combat disorder* OR war neurosis OR Schreckneurose OR fright neuroses OR shell shock OR sex*-abus* OR sex* abus* OR terror* OR war OR conflict* OR violen* OR acciden* OR shoot* OR disaster* OR earthquake OR tornado OR flood OR tsunami* OR hurricane* OR fire OR maltreat* OR crash* OR death OR grief) AND Intervention = (psychother* OR psychological OR cognitive-behavio* OR cognitive-behavio* OR behavio* OR cogniti* OR CBT OR exposure therapy OR exposure treatment OR exposure-based behavior therapy OR exposure-based OR exposure*).

Our inclusion criteria were as follows: (i) randomized controlled trials (RCTs); (ii) participants were children and adolescents (aged $\leq 18$ years) who met the criteria for PTSD diagnosis: a. for patients with complete PTSD, according to the standardized diagnosis based on the international classification (the Diagnostic and Statistical Manual of Mental Disorders [DSM] ${ }^{26-30}$, the International Classification of Diseases [ICD] ${ }^{31,32}$ or validated scales for PTSD based on DSM/ICD criteria $\left.{ }^{33-36}\right)$; b. patients with subclinical PTSD, defined as those who have experienced psychological trauma, present with at least one of the four symptom groups described in DSM- 5 and reported some subsequent symptoms of PTSD, including re-experiencing, avoidance, overreaction, and negative cognitive and emotional changes; c. patients with clinically significant symptoms of PTSD, that was, the score of the patient scale was higher than the effective threshold of the PTSD rating scale; (iii) the intervention was exposure therapy, including PE, NET, KIDNET, etc.; (iv) there were more than ten participants per study; (v) the interventions of the control group were active control groups (ACG), treatment as usual (TAU), and waiting list (WL). The ACG could include supportive unstructured psychotherapy, nondirective supportive treatment and child-centered therapy.

The initial screening was based on the title and abstract by two researchers (H.L and T.H.) independently. Publications were excluded from the search results if they did not meet the aforementioned inclusion criteria. Any disagreement during the process was resolved by discussing with senior review authors (Y.X and $X . Z$ ). If the data that was necessary for conducting the analysis were missing from a publication, we contacted and requested the corresponding author to provide the data. If the authors did not respond with the sufficient data to perform the meta-analysis or even did not respond us, the studies were excluded.

\section{Data Extraction}

Two independent reviewers (T.H and H.L) extracted the relevant parameters from the original paper, including the titles of the studies, patient characteristics (including type of trauma, diagnostic criteria for PTSD, severity of PTSD symptoms, the sample size, mean age and gender of participants), intervention details (including type of interventions, number of sessions, treatment duration, follow-up duration). If there was a disagreement between two reviewers, we resolved the disagreement by discussing with the senior review authors (Y.X and X.Z).

\section{Quality Assessment}

Two reviewers (S.T and S.X) assessed the methodological quality of the included studies independently. According to the Cochrane Collaboration's tool V.2.0, the risk of bias was rated as 'low risk', 'high risk' or 'some concerns' in the following domains: (1) bias arising from the randomization process; (2) bias due to deviations from intended interventions; (3) bias due to missing outcome data; (4) bias in measurement of the outcome; (5) bias in selection of the reported result. The disagreement between two reviewers was resolved by discussing with the senior review authors (Y.X and X.Z).

\section{Outcomes}

The primary outcomes were the efficacy (as measured by the endpoint score from PTSD symptom severity rating scales completed by children, parents or clinicians) and acceptability (as the percentage of people who had dropped out from the study for any reason) of post-treatment. Reliable and effective assessment methods were adopted such as the Child PTSD Symptom Scale-Interview (CPSS-I), the Clinician-Administered PTSD Scale (CAPs), etc. were used to measure the curative effect of treatment of complete exposure therapy. If more than one scale was reported in a trial, we chose the scale with the highest ranking according to a hierarchy based on psychometric properties and appropriateness, which was defined in our previous registered protocol. If the trial had different raters of the assessment of PTSD symptom severity rating scale, we gave priority to use self-report ${ }^{37}$. Secondary outcomes included efficacy at follow-up (measured by the score from PTSD scales at the longest point of follow-up up to 12 months), depressive symptoms (measured by the end-point score on depressive symptom severity rating scales), quality of life and functional improvement (QoL/functioning) (measured by the end-point score on QoL/functioning rating scales).

\section{Statistical analysis}

Analyses were conducted by using the Review Manager, Version 5.3 and Stata 16.0. Continuous variables were estimated by calculating pooled standardized mean differences (SMD, hedge's $\mathrm{g}$ ) and $95 \%$ confidence intervals (Cls). The binary variables were estimated by calculating pooled odds ratios (ORs) and $95 \%$ Cls. The significance of the pooled SMDs or ORs was estimated by $Z$ test $\left(P<0.05\right.$ was considered statistically significant). The $I^{2}$-based $Q$ statistic test was performed to evaluate variations due to heterogeneity rather than chance. A random-effects or fixed effects methods model was used to calculate pooled effect estimates in the presence $(P<0.05)$ or absence $(P \geq 0.05)$ of heterogeneity. we assign adjectives of low, moderate, and high to $I^{2}$ values of $25 \%, 50 \%$, and $75 \%^{38}$. We used funnel plots to detect publication bias, which was performed in Stata $16.0^{39}$. 
Considering the possibility that effectiveness may differ according to the different parameters, we conducted various subgroup analyses of the parameters as following: (1) single type of trauma vs. multiple types of trauma (suffering more than one type of trauma); (2) PE vs. NET vs. KIDNET; (3) treatment duration > 12 weeks vs. $\leq 12$ weeks $^{40}$. We also performed sensitivity analyses by omitting RCTs, which was published in a significantly different year than the others, or with non-blinding assessment, or was small sample-size (sample size was less than others), etc. may have significant bias on the results based on the characteristics of the article. All tests were two-sided, and statistical significance was defined as a probability $\mathrm{P}$ value of $<0.05$.

\section{Results}

\section{Study Characteristics}

Through searching the databases and international trials registers mentioned above, 10,105 citations were identified and 112 potentially eligible articles were retrieved in full text. In total, 6 clinical trials were included in the present study. The flow diagram was shown in figure 1 . Six randomized controlled trials $(n=$ 278) comparing ET ( $n=145)$ with control conditions $(n=133)$ were included, the clinical and methodological characteristics of included trials were summarized in table 1. The mean age was 13.84 years old $(S D=2.33)$ and $69.1 \%$ were females. Two RCTs ${ }^{41,42}(33.33 \%)$ were conducted in Sri Lanka $(n=78)$, and four (66.67\%) from other countries (Germany, Finland, South Africa, etc.). The mean study sample size was 46 , ranging between 26 and 63 patients. Trauma types included trauma from the $\operatorname{war}^{41}(n=78)$, sexually abused ${ }^{43}(n=61), \operatorname{mixed}^{44}(n=123)$ and others.

\section{Primary Outcomes}

For efficacy at post-treatment in PTSD symptom severity, 6 articles $(n=257)$ were included ${ }^{24,42,44-46}$. The results showed that ET perform more efficaciously than control groups (SMD: $-0.47,95 \% \mathrm{Cl}:-0.91$ to -0.03$)$ with a moderate significant heterogeneity $\left(\mathrm{I}^{2}=66 \%, \mathrm{P}=0.01\right.$, Fig. $\left.2 \mathrm{~A}\right)$. For acceptability, 6 studies $^{24,42-46}(n=278)$ were included and there were no significant differences between the treatment group and the control group (OR: 0.88 , $95 \% \mathrm{Cl}$ : 0.42 to 1.84) with no significant heterogeneity $\left(I^{2}=0 \%, P=0.78\right.$, Fig. $\left.2 B\right)$.

\section{Secondary Outcomes}

For the effects of follow-up, 4 studies ${ }^{42,43,45,46}$ were eligible $(n=163)$. Exposure therapy was statistically significantly more efficacious than control conditions (SMD: $-0.64,95 \% \mathrm{Cl}:-1.17$ to -0.10$)$ with moderate heterogeneity among studies $\left(I^{2}=62 \%, P=0.05\right.$, Fig. $\left.3 A\right)$. For the effect of treatment on depressive symptoms, we included 3 studies $^{24,43,45}(n=130)$, and the exposure therapy were more efficacious than control groups (SMD: $-0.58,95 \% \mathrm{Cl}:-0.93$ to -0.22$)$ with non-significant low heterogeneity $\left(I^{2}=51 \%, P=0.13\right.$, Fig. 3B). In terms of the effects of quality of life/social functioning, three trials ${ }^{42,43,45}$ ( $\left.n=136\right)$ were included, it showed that there were no significant differences at the end of treatment (SMD: $0.15,95 \% \mathrm{Cl}:-0.47$ to 0.76 ) with statistically significant moderate heterogeneity $\left(I^{2}=68 \%, P=0.04\right.$, Fig. $\left.3 C\right)$.

\section{Subgroup Analysis}

For subgroup analysis of the efficacy at post-treatment, among patients who suffered multiple types of trauma, no significant difference was found between exposure therapy and control groups (SMD: $-0.11,95 \% \mathrm{Cl}:-0.45$ to $0.22 ; \mathrm{I}^{2}=0 \%, \mathrm{P}=0.50$, Fig. $4 \mathrm{~A}$ ). For patients who suffered single type of trauma, exposure therapy was statistically more efficacious than control groups (SMD: $-1.04,95 \% \mathrm{Cl}:-1.43$ to $-0.65 ; \mathrm{I}^{2}=0 \%, \mathrm{P}=0.99$ ). The intervention method using $\mathrm{PE}$ as the experimental groups (SMD: $-1.04,95 \% \mathrm{Cl}:-1.43$ to $-0.65 ; \mathrm{I}^{2}=0 \%, \mathrm{P}=0.99$, Fig. $4 \mathrm{~B}$ ) were more effective than control groups, but groups using NET (SMD: 0.01 , $95 \% \mathrm{Cl}:-0.42$ to $0.43 ; \mathrm{I}^{2}=0 \%, \mathrm{P}=0.73$ ) or KIDNET (SMD: $-0.31,95 \% \mathrm{Cl}:-0.96$ to $0.33 ; \mathrm{I}^{2}=32 \%, \mathrm{P}=0.23$ ) were not. For patients whose treatment sessions were more than 12 weeks (SMD: $-0.55,95 \% \mathrm{Cl}:-1.51$ to $0.41 ; \mathrm{I}^{2}=82 \%, \mathrm{P}=0.02$, Fig. $4 \mathrm{C}$ ) or less (SMD: $-0.42,95 \% \mathrm{Cl}:-1.00$ to $0.16 ; \mathrm{I}^{2}=68 \%, \mathrm{P}=0.03$ ), exposure therapy was not more effective than control groups.

\section{Quality Assessment And Publication Bias}

In terms of study quality from ROB 2.0, two RCT ${ }^{42,37}$ was rated as low risk, and four RCTs ${ }^{24,43-46}$ were rated as some concerns (Fig. 5). In addition, for the publication bias, we inspected the inverted funnel plots of these studies visually, which appeared to be approximately symmetrical. This suggested no significant publication bias.

\section{Discussion}

This meta-analysis is aimed to assess the efficacy and acceptability of exposure therapy in the treatment of PTSD in children and adolescents. To our knowledge, this is the first time that exposure therapy for PTSD in children and adolescents have been compared in a metaanalysis. We found that exposure therapy showed better efficacy than control groups at post-treatment/follow-up and depressive symptom, but the acceptability did not perform better. Subgroup analysis showed that patients with single type of trauma may benefit more from exposure therapy. And PE showed a significantly advantage. This meta-analysis may provide some new sights for the clinical treatment of PTSD in children and adolescents. 
It has been proved that ET showed a significant advantage $\mathrm{e}^{40,47}$ and was recommended as the first-line therapy for adults' PTSD ${ }^{16,40}$. The present study showed a similar result in terms of PTSD in children and adolescents. Owing to the mechanisms of ET, it can active the traumatic memory and inserted the safe components ${ }^{15,48}$, so that ET can have good efficacy of PTSD. Besides, subgroup analysis showed a signi[cantly advantage for PE. The possible reasons for could be the following: Firstly, PE was an exposure-based CBT of PTSD and has been in development since $1982^{16}$. Therefore, PE was the widely studied psychotherapy with more comprehensive evidence for PTSD. Secondly, PE is an extensively studied form of individual CBT, the adaptation emphasizes developmental sensitivity, modularity, and flexibility ${ }^{16}$. In addition to core ET components of psychoeducation and exposure, PE included more extensive case management and relapse prevention component, those could contribute to the beneficial of $\mathrm{PE}^{16}$. While for NET, the fear structure needed to be activated in a safe environment to decrease maladaptive associations ${ }^{19}$. However, during re-experiencing of the traumatic events (such as through nightmares, intrusive thoughts, or flashbacks), the fear network became reinforced because of the additional layer of emotional distress, and the memory was thus more susceptible to being triggered later ${ }^{19}$. On the other hand, subgroup analysis showed that exposure therapy was more effective for children and adolescents with single type of trauma. But due to the low number of studies, the results should be treated with caution. The trauma types of patients in the present study were more comprehensive compared with the previous study ${ }^{49}$. Four out of six studies in the meta-analysis included patients with multiple types of trauma. For example, one of our studies ${ }^{44}$ included the teenagers who suffered natural disasters, traffic accidents, or sexual assault. These results were consistent with previous studies ${ }^{50,51}$. Since patients who experienced multiple types of trauma, had more possibility to have complex PTSD including (in addition to the core PTSD symptoms of re-experiencing, avoidance, and hyperarousal) disturbances in affect regulation, dissociation, self-concept, interpersonal relationships, somatization, and systems of meaning ${ }^{52}$. Complex mental illnesses may have a negative impact on the treatment results of PTSD patients ${ }^{53}$, leading to unhealed trauma, and uncured trauma was a common cause of refractory depression and obsessive-compulsive disorder ${ }^{54}$.

Our analysis suggest that ET may generally result in better outcomes than control conditions in long-term follow-up. When treating children and adolescents with trauma, it may be important not only to tackle one event in their traumatic history, but to process all events that still cause PTSD symptom. The clinical model of repeated traumatization underlying ET drew on dual representation theories of PTSD and emotional processing theory and the idea of fear networks ${ }^{55}$. ET constructed a narrative that covers the patient's entire life, while giving a detailed account of past traumatic experiences, which could contribute to the long-term efficacy ${ }^{16}$. For acceptability, no significant different was observed between ET and control groups. However, from the patient's perspective, especially for children and adolescents, exposure therapy was challenging and its treatment process was relatively painful ${ }^{15}$, it required the patient to reproduce the traumatic experience, and may cause adverse effects on the patient. The treatment cycle was also relatively long ${ }^{16}$.

Because PTSD patients usually had comorbidities, such as depression and anxiety ${ }^{56,57}$, we also considered the efficacy of exposure therapy for PTSD comorbidities. This study showed that exposure therapy can significantly improve patients' depressive symptoms. Regarding the mechanism of its effect on depression symptoms, despite the lack of Socratic questioning, specific instruction about cognitive errors, and assigned practice, ET may change depression through cognitive shifts, or the mechanism may be the emotional arousal via exposure ${ }^{58}$. The specific mechanism was still unclear. However, those could provide some signs that ET could be an efficacious choice for PTSD patient comorbidity with depressive symptoms in children and adolescents. The patient's quality of life at the end of treatment has not been greatly improved. We speculated that this may be related to the relatively painful process of exposure therapy and further researches are needed.

Overall, our results provided some new perspectives on exposure therapy for PTSD in children and adolescents. We have tried to reduce heterogeneity by omitting RCTs that may cause significant bias in the results due to article characteristics (such as unreasonable research design, non-RCT, sample size less than 10, etc.). However, due to the following limitations, the results of this meta-analysis should be interpreted with caution. First of all, this study included a small sample size. The scope of our literature search was as wide as possible, but after screening in strict accordance with the standards, only 6 studies were included. Reasons for the low number of studies include: 1) for the high drop-out rate, there were not many RCTs for children and adolescents with PTSD, however, the mental health of children and adolescents was essential to the sustainable development of society, which is why we adhered to this theme. The reasons of high drop-out rate may include: a. either the child's/adolescent's or his or her parents' decision not to continue the treatment because they felt that the treatment was no longer needed ${ }^{24}$. b. Some NET clients reported that it was too hard to go through the traumatic events and wanted to quit ${ }^{24}$. c. Many times the child populations in wars are on the move. 'Home' is often a Displaced People's Camp, a Cross border Transit or Refugee Camp. It is challenging to extend individual services, which last several weeks if not months. ${ }^{44}$; 2) psychotherapy for children and adolescents required systematic and standardized training, which was more difficult than better quantitative evaluation of drug therapy; 3 ) exposure therapy can evoke traumatic memories in children and adolescents. Secondly, most of the analysed outcomes presented with moderate to high heterogeneity. Those could come from the clinical and methodological characteristics. Some subgroup analyses were conducted to explore the potential sources of heterogeneity, however, other important parameter such as symptom severity, gender, age, country of patients couldn't not be addressed due to the limitation of original data. Thirdly, the ROB 2.0 showed most of the risk of bias of the included studies was rated as low risk and some concerns. These mainly came from the deviations from intended interventions, for the blinding. However, it was difficult to conduct with double-blinding in psychotherapies.

\section{Conclusion}

This meta-analysis found that ET showed superiority in terms of efficacy at post-treatment/follow-up and depressive symptoms improvement in treating PTSD in children and adolescents. Patients with single type of trauma may benefit more from the intervention of ET. Moreover, PE could be a better choice for children and adolescents with PTSD. Further well-defined clinical studies should be conducted to confirm those outcomes.

\section{Declarations}

\section{Ethics approval and consent to participate}


Not applicable

\section{Consent for publication}

Not applicable

\section{Availability of data and materials}

The datasets analysed during the current study are available in the Mendeley repository, at http://doi.org/10.17632/d6m4xhwtyw.3.

\section{Competing interests}

XZ reported receiving lecture fees from Janssen Pharmaceutica and Lundbeck, outside the submitted work. All other authors declare no competing interest.

\section{Funding}

This study is supported by the National Natural Science Foundation of China (grant 81873800); the High-level Talents Special Support Plan of Chongqing (grant T04040016) and the institutional funds from the Chongqing Science and Technology Commission (grant cstc2020jcyj-jqX0024).

\section{Authors' contributions}

T.H. and H.L. contributed equally to this work. X. Z. and Y. X. share the senior author position. H.L. and T.H. wrote the main manuscript text.All authors contributed to the writing of the manuscript text. S.T. and S.X. assessed the methodological quality of the included studies independently. S.T. and T.H. prepared figures. S.X. prepared table 1. All authors reviewed the manuscript.

\section{Acknowledgments}

Not applicable

\section{References}

1. Kessler RC, Galea S, Gruber MJ, Sampson NA, Ursano RJ, Wessely S. Trends in mental illness and suicidality after Hurricane Katrina. Mol Psychiatry 2008; 13(4): 374-84.

2. Arnberg FK, Gudmundsdóttir R, Butwicka A, et al. Psychiatric disorders and suicide attempts in Swedish survivors of the 2004 southeast Asia tsunami: a 5 year matched cohort study. Lancet Psychiatry 2015; 2(9): 817-24.

3. North CS, Smith EM, Spitznagel EL. One-year follow-up of survivors of a mass shooting. Am J Psychiatry 1997; 154(12): 1696-702.

4. Lancaster SL, Melka SE, Rodriguez BF, Bryant ARJJoAM, Trauma. PTSD Symptom Patterns Following Traumatic and Nontraumatic Events. Journal of Aggression Maltreatment \& Trauma 2014; 23(4): 414-29.

5. Luthra R, Abramovitz R, Greenberg R, et al. Relationship between type of trauma exposure and posttraumatic stress disorder among urban children and adolescents. J Interpers Violence 2009; 24(11): 1919-27.

6. McLaughlin KA, Koenen KC, Hill ED, et al. Trauma exposure and posttraumatic stress disorder in a national sample of adolescents. Journal of the American Academy of Child and Adolescent Psychiatry 2013; 52(8).

7. Alisic E, Zalta AK, van Wesel F, et al. Rates of post-traumatic stress disorder in trauma-exposed children and adolescents: meta-analysis. Br J Psychiatry 2014; 204: 335-40.

8. Lamberg L. Psychiatrists explore legacy of traumatic stress in early life. JAMA 2001; 286(5): 523-6.

9. Merz J, Schwarzer G, Gerger H. Comparative Efficacy and Acceptability of Pharmacological, Psychotherapeutic, and Combination Treatments in Adults With Posttraumatic Stress Disorder: A Network Meta-analysis. JAMA Psychiatry 2019.

10. Panagioti M, Gooding P, Tarrier N. Post-traumatic stress disorder and suicidal behavior: A narrative review. Clin Psychol Rev 2009; 29(6): 471-82.

11. Guidelines for treatment of PTSD. Journal of traumatic stress 2000; 13(4): 539-88.

12. Ponteva M, Henriksson M, Isoaho R, Laukkala T, Punamäki L, Wahlbeck K. [Update on Current Care Guidelines: Post-traumatic Stress Disorder]. Duodecim; laaketieteellinen aikakauskirja 2015; 131(6): 558-9.

13. Summary of the practice parameters for the assessment and treatment of children and adolescents with posttraumatic stress disorder. American Academy of Child and Adolescent Psychiatry. Journal of the American Academy of Child and Adolescent Psychiatry 1998; 37(9).

14. Morina N, Koerssen R, Pollet TV. Interventions for children and adolescents with posttraumatic stress disorder: A meta-analysis of comparative outcome studies. Clin Psychol Rev 2016; 47: 41-54.

15. Foa EB, Kozak MJ. Emotional processing of fear: exposure to corrective information. Psychol Bull 1986; 99(1): 20-35.

16. Mørkved N, Hartmann K, Aarsheim LM, et al. A comparison of Narrative Exposure Therapy and Prolonged Exposure therapy for PTSD. Clin Psychol Rev 2014; 34(6): 453-67.

17. Cukor J, Olden M, Lee F, Difede J. Evidence-based treatments for PTSD, new directions, and special challenges. Ann N Y Acad Sci 2010; 1208: 82-9.

18. Foa EB, Hembree, E., \& Rothbaum, B. O. Prolonged exposure therapy for PTSD: Emotional processing of traumatic experiences therapist guide. USA Oxford University Press 2007; Vol. 1. 
19. Schauer M, Neuner, F., \& Elbert, T. . Narrative exposure therapy: A short-term treatment for traumatic stress disorders (2nd rev. and expanded ed.). Cambridge, MA: Hogrefe Publishing; US 2011.

20. Onyut LP, Neuner F, Schauer E, et al. Narrative Exposure Therapy as a treatment for child war survivors with posttraumatic stress disorder: Two case reports and a pilot study in an African refugee settlement. 2005; 5(1): 1-9.

21. Kangaslampi S, Garoff F, Peltonen K. Narrative exposure therapy for immigrant children traumatized by war: study protocol for a randomized controlled trial of effectiveness and mechanisms of change. BMC Psychiatry 2015; 15: 127.

22. Markowitz JC, Petkova E, Neria Y, et al. Is Exposure Necessary? A Randomized Clinical Trial of Interpersonal Psychotherapy for PTSD. Am J Psychiatry 2015; 172(5): 430-40.

23. Landowska A, Roberts D, Eachus P, Barrett A. Within- and Between-Session Prefrontal Cortex Response to Virtual Reality Exposure Therapy for Acrophobia. Frontiers in human neuroscience 2018; 12: 362.

24. Peltonen K, Kangaslampi S. Treating children and adolescents with multiple traumas: a randomized clinical trial of narrative exposure therapy. European journal of psychotraumatology 2019; 10(1): 1558708.

25. Moher D, Liberati A, Tetzlaff J, Altman DG. Preferred reporting items for systematic reviews and meta-analyses: the PRISMA statement. J Clin Epidemiol 2009; 62(10): 1006-12.

26. Association AP. Diagnostic and statistical manual of mental disorders. 5th edn. Arlington, VA: American Psychiatric Publishing 2013.

27. (APA) APA. Diagnostic and statistical manual of mental disorders (DSM-III). 3rd edn. Washington DC: American Psychiatric Association 1980.

28. (APA) APA. Diagnostic and statistical manual of mental disorders (DSM-III-R). 3rd edn. Washington DC: American Psychiatric Association 1987.

29. (APA) APA. Diagnostic and statistical manual of mental disorders (DSM-IV). 4th edn. Washington DC: American Psychiatric Association 1994.

30. (APA) APA. Diagnostic and statistical manual of mental disorders (DSM-IV-TR). 4th edn. Washington DC: American Psychiatric Association 2000.

31. (WHO) WHO. The Ninth Revision of the International Classification of Diseases and related health problems (ICD-9). Geneva: World Health Organization 1978.

32. (WHO) WHO. The Tenth Revision of the International Classification of Diseases and related health problems (ICD-10). Geneva: World Health Organization 1992.

33. Nader KO NE, Weathers FW, et al. Clinician-Administered PTSD scale for children and adolescents for DSM-IV (CAPS-CA). Los Angeles, USA: National Center for PTSD \& UCLA Trauma Psychiatry Program collaboration 1998.

34. Pynoos RS RN, Steinberg A, et al. The UCLA PTSD Reaction Index for DSM-IV (Revision 1). Los Angeles: UCLA Trauma Psychiatry Program 1998.

35. Kaufman J BB, Brent D, et al. Schedule for affective disorders and schizophrenia for school-age children-present and lifetime version (K-SADS-PL): initial reliability and validity data. J Am Acad Child Adolesc Psychiatry 1997;36:980-8.

36. Silverman WK AA. Anxiety disorders interview schedule for DSM-IV: child and parent versions. San Antonio, TX: Psychological Corporation 1996.

37. Moshier SJ, Bovin MJ, Gay NG, et al. Examination of posttraumatic stress disorder symptom networks using clinician-rated and patient-rated data. $J$ Abnorm Psychol 2018; 127(6): 541-7.

38. Higgins J, Thompson SG, Decks JJ, Altman DGJBMJ. Measuring inconsistency in meta-analyses. 2003; 327(7414): p.557-60.

39. ZHOU Wei ZY, MENG Huaqing, DENG Guolan, ZHOU Xinyu. Efficacy and safety of newer-generation antidepressants for patient with myocardial infarction and depression: a meta-analysis. Chinese Journal of Evidence-based Medicine 2018; 18(7): 715-20.

40. Cusack K, Jonas DE, Forneris CA, et al. Psychological treatments for adults with posttraumatic stress disorder: A systematic review and meta-analysis. Clin Psychol Rev 2016; 43: 128-41.

41. Neuner F, Catani C, Ruf M, Schauer E, Schauer M, Elbert T. Narrative exposure therapy for the treatment of traumatized children and adolescents (KidNET): from neurocognitive theory to field intervention. Child and adolescent psychiatric clinics of North America 2008; 17(3).

42. Catani C, Kohiladevy M, Ruf M, Schauer E, Elbert T, Neuner F. Treating children traumatized by war and Tsunami: a comparison between exposure therapy and meditation-relaxation in North-East Sri Lanka. BMC Psychiatry 2009; 9: 22.

43. Foa EB, Mclean CP, Capaldi S, Rosenfield DJJtJotAMA. Prolonged exposure vs supportive counseling for sexual abuse-related PTSD in adolescent girls: a randomized clinical trial. 2013; 310(24): 2650-7.

44. E S. Trauma treatment for children in war: build-up of an evidence-based large-scale mental health intervention in north-eastern Sri Lanka. Konstanz University of Konstanz 2008

45. Rossouw J, Yadin E, Alexander D, Seedat S. Long-term follow-up of a randomised controlled trial of prolonged exposure therapy and supportive counselling for post-traumatic stress disorder in adolescents: a task-shifted intervention. Psychological Medicine 2020: 1-9.

46. Ruf M, Schauer M, Neuner F, Catani C, Schauer E, Elbert T. Narrative exposure therapy for 7-to 16-year-olds: a randomized controlled trial with traumatized refugee children. J Trauma Stress 2010; 23(4): 437-45.

47. Rauch SA, Eftekhari A, Ruzek JI. Review of exposure therapy: a gold standard for PTSD treatment. J Rehabil Res Dev 2012; 49(5): 679-87.

48. McNally RJ. Mechanisms of exposure therapy: how neuroscience can improve psychological treatments for anxiety disorders. Clin Psychol Rev 2007; 27(6): 750-9.

49. Gilboa-Schechtman E, Foa EB, Shafran N, et al. Prolonged Exposure Versus Dynamic Therapy for Adolescent PTSD: A Pilot Randomized Controlled Trial. Journal of the American Academy of Child \& Adolescent Psychiatry 2010; 49(10): 1034-42.

50. Priebe K, Kleindienst N, Schropp A, et al. Defining the index trauma in post-traumatic stress disorder patients with multiple trauma exposure: impact on severity scores and treatment effects of using worst single incident versus multiple traumatic events. Eur J Psychotraumatol $2018 ; 9$ (1): 1486124.

Page 7/11 
51. Loos S, Wolf S, Tutus D, Goldbeck L. [Frequency and Type of Traumatic Events in Children and Adolescents with a Posttraumatic Stress Disorder]. Prax Kinderpsychol Kinderpsychiatr 2015; 64(8): 617-33.

52. Ottisova L, Smith P, Oram S. Psychological Consequences of Human Trafficking: Complex Posttraumatic Stress Disorder in Trafficked Children. Behavioral Medicine 2018; 44(3): 234-41.

53. Goddard E, Wingrove J, Moran P. The impact of comorbid personality difficulties on response to IAPT treatment for depression and anxiety. Behaviour Research and Therapy 2015; 73: 1-7.

54. Ho GWK, Hyland P, Shevlin M, et al. The validity of ICD-11 PTSD and Complex PTSD in East Asian cultures: findings with young adults from China, Hong Kong, Japan, and Taiwan. Eur J Psychotraumatol 2020; 11(1): 1717826.

55. McLean CP, Foa EB. Prolonged exposure therapy for post-traumatic stress disorder: a review of evidence and dissemination. Expert Rev Neurother 2011; 11(8): 1151-63.

56. Kessler RC, Chiu WT, Demler O, Merikangas KR, Walters EE. Prevalence, severity, and comorbidity of 12-month DSM-IV disorders in the National Comorbidity Survey Replication. Archives of general psychiatry 2005; 62(6): 617-27.

57. Kessler RC, Sonnega A, Bromet E, Hughes M, Nelson CB. Posttraumatic stress disorder in the National Comorbidity Survey. Archives of general psychiatry 1995; 52(12): 1048-60.

58. Thompson-Hollands J, Marx BP, Lee DJ, Resick PA, Sloan DM. Long-term treatment gains of a brief exposure-based treatment for PTSD. Depress Anxiety 2018; 35(10): 985-91.

\section{Tables}

Table 1: Randmised controlled trials included in the systematic review and meta-analysis

\begin{tabular}{|c|c|c|c|c|c|c|c|c|c|c|c|}
\hline Trial & $\begin{array}{l}\text { Type of } \\
\text { trauma }\end{array}$ & $\begin{array}{l}\text { Diagnostic } \\
\text { criteria }\end{array}$ & $\begin{array}{l}\text { Treatments } \\
\text { (number of } \\
\text { sessions) }\end{array}$ & $\begin{array}{l}\text { No. } \\
\text { randomised }\end{array}$ & $\begin{array}{l}\text { Age } \\
\text { range } \\
\text { and } \\
\text { mean } \\
\text { age } \\
\text { (years) }\end{array}$ & $\begin{array}{l}\text { Proportion } \\
\text { of female } \\
(\%)\end{array}$ & Recruitment & $\begin{array}{l}\text { Baseline } \\
\text { severity } \\
\text { scale }\end{array}$ & $\begin{array}{l}\text { Mean } \\
\text { baseline } \\
\text { severity } \\
\text { (SD) }\end{array}$ & $\begin{array}{l}\text { Treatment } \\
\text { Duration, } \\
\text { (w) }\end{array}$ & $\begin{array}{l}\text { Follor } \\
\text { up } \\
\text { Durat } \\
\text { (m) }\end{array}$ \\
\hline $\begin{array}{l}\text { Catani } \\
2009\end{array}$ & $\begin{array}{l}\text { War and } \\
\text { Tsunami }\end{array}$ & Full PTSD & $\begin{array}{l}\text { KIDNET (6) } \\
\text { WL (6) }\end{array}$ & $16 / 15$ & $\begin{array}{l}\text { 8-14 } \\
(11.9)\end{array}$ & $45.2 \%$ & Sri Lanka & $\begin{array}{l}\text { UCLA } \\
\text { PTSD } \\
\text { Index }\end{array}$ & $\begin{array}{l}37.9 \\
(14.2)\end{array}$ & 2 & 6 \\
\hline $\begin{array}{l}\text { Foa } \\
2013\end{array}$ & $\begin{array}{l}\text { Sexual } \\
\text { abuse }\end{array}$ & $\begin{array}{l}\text { Full PTSD } \\
\text { and } \\
\text { Subclinical } \\
\text { PTSD }\end{array}$ & $\begin{array}{l}\text { PE (14) } \\
\text { ACG (14) }\end{array}$ & $31 / 30$ & $\begin{array}{l}13-18 \\
(15.3)\end{array}$ & $100.0 \%$ & Germany & CPSS-I & $\begin{array}{l}27.3 \\
(7.4)\end{array}$ & 14 & 12 \\
\hline $\begin{array}{l}\text { Peltonen } \\
2019\end{array}$ & Mixed* & $\begin{array}{l}\text { Subclinical } \\
\text { PTSD }\end{array}$ & $\begin{array}{l}\text { NET (10) } \\
\text { TAU (ND) }\end{array}$ & $29 / 21$ & $\begin{array}{l}9-17 \\
(13.2)\end{array}$ & $42.0 \%$ & Finland & CRIES & $\begin{array}{l}38.3 \\
(14.4)\end{array}$ & 10 & 3 \\
\hline $\begin{array}{l}\text { Rossouw } \\
2018\end{array}$ & $\begin{array}{l}\text { Interpersonal } \\
\text { trauma }\end{array}$ & Full PTSD & $\begin{array}{l}\text { PE (7-14) } \\
\text { ACG (7-14) }\end{array}$ & $31 / 32$ & $\begin{array}{l}13-18 \\
(15.4)\end{array}$ & $87.3 \%$ & $\begin{array}{l}\text { South } \\
\text { Africa }\end{array}$ & CPSS-I & $\begin{array}{l}34.5 \\
(8.2)\end{array}$ & $7-14$ & 6 \\
\hline $\begin{array}{l}\text { Ruf } \\
2010\end{array}$ & Mixed** & Full PTSD & $\begin{array}{l}\text { KIDNET(8) } \\
\text { WL (8) }\end{array}$ & $13 / 13$ & $\begin{array}{l}7-16 \\
(11.5)\end{array}$ & $46.2 \%$ & Multiple*** & $\begin{array}{l}\text { UCLA } \\
\text { PTSD } \\
\text { Index }\end{array}$ & $\begin{array}{l}43.3 \\
(12.3)\end{array}$ & 4 & 6 \\
\hline $\begin{array}{l}\text { Schauer } \\
2008\end{array}$ & Mixed ${ }^{\star \star \star \star}$ & Full PTSD & $\begin{array}{l}\text { NET (6) } \\
\text { ACG (6) }\end{array}$ & $25 / 22$ & $\begin{array}{l}11-14 \\
(13.1)\end{array}$ & $61.7 \%$ & Sri Lanka & $\begin{array}{l}\text { CAPS- } \\
\text { CA }\end{array}$ & $\begin{array}{l}63.2 \\
(17.7)\end{array}$ & 20 & 13 \\
\hline
\end{tabular}

Abbreviations: $\mathrm{PE}=$ Prolonged Exposure Therapy, NET = Narrative Exposure Therapy, KIDNET = Narrative Exposure Therapy for children, ACG = Active Treatment Group, WL = waiting list, TAU = treat as usual, UCLA PTSD Index = University of California, Los Angeles Post-Traumatic Stress Disorder Reaction Index, CPSS-I = Child PTSD Symptom Scale-Interview, CRIES = The Children's Revised Impact of Events Scale, CAPS = Clinician-Administered PTSD Scale, NA

$=$ Not Available, $\mathrm{w}=$ week, $\mathrm{m}=$ month.

* Refugeedom (war), Family violence.

** Children had experienced an average of four different traumatic event types, mostly prior to leaving their country of origin. Violent attacks against their parents or other family members at home were the most common.

***Turkey (Kurdish) /Balkan/ Syria/ Chechnya/ Russia/Georgia/ Germany (Balkan)

${ }^{\star \star \star \star}$ According to the classification of researchers, more than 16 types of trauma were included. Such as natural disasters, traffic accidents, sexual assault, etc. 


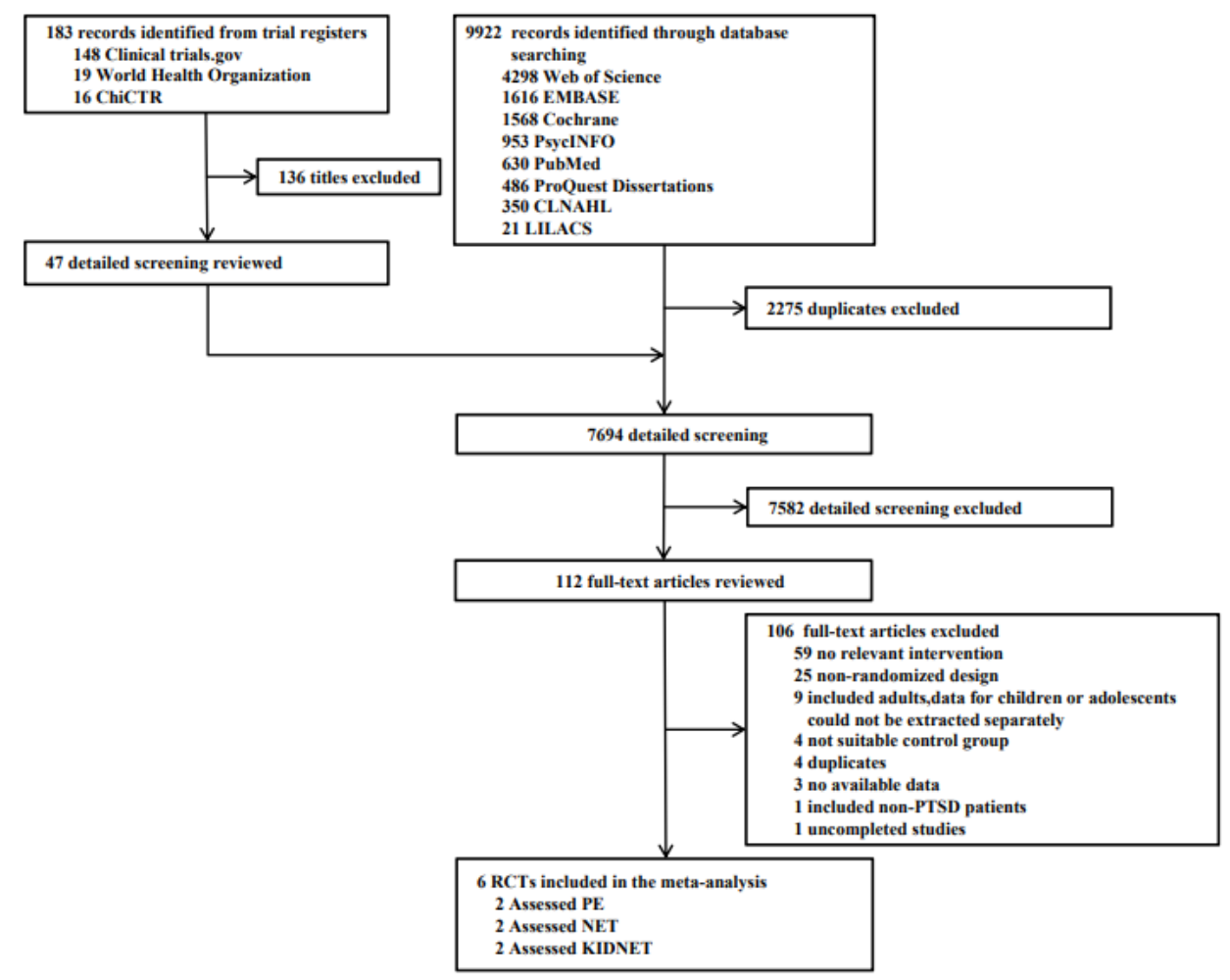

Figure 1

Flow chart of study selection. Abbreviations: PE = Prolonged Exposure Therapy, NET = Narrative Exposure Therapy, KIDNET = Narrative Exposure Therapy for children.

A

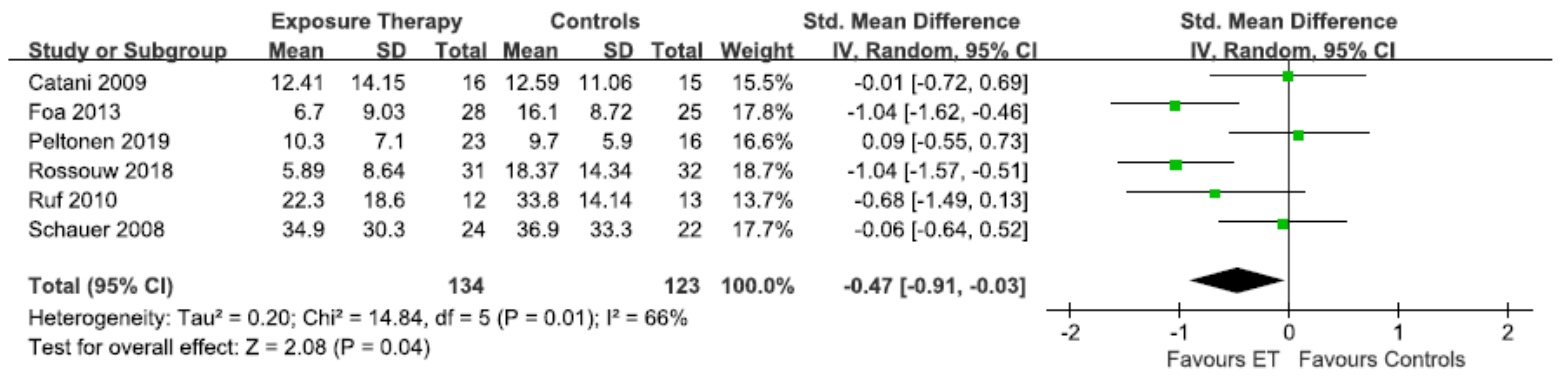

B

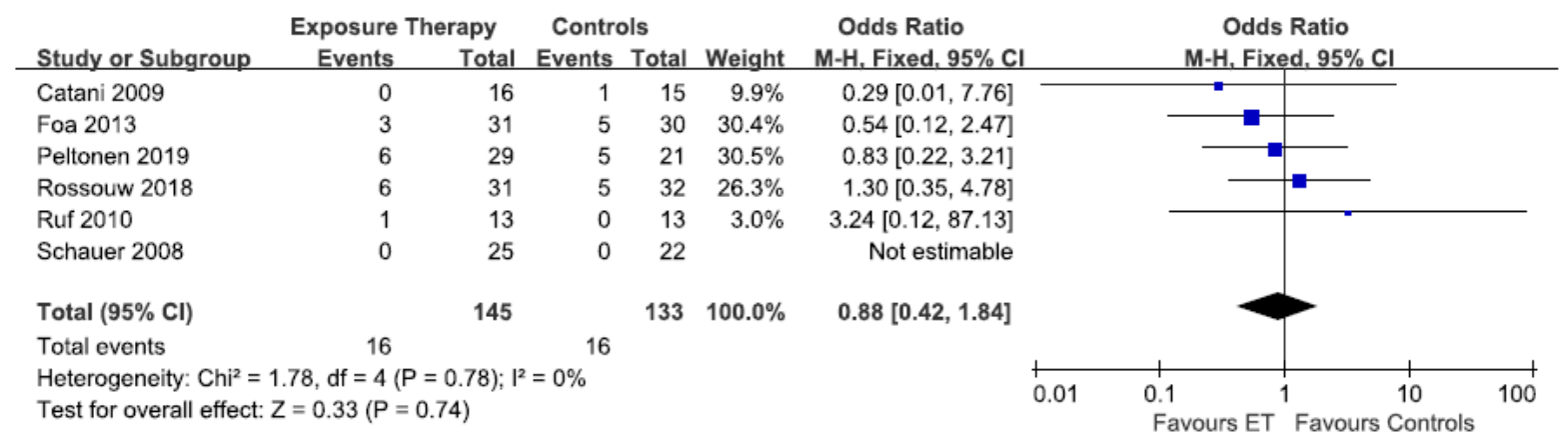

\section{Figure 2}

The efficacy (A) and acceptability (B) of exposure therapy at post-treatment. 
A

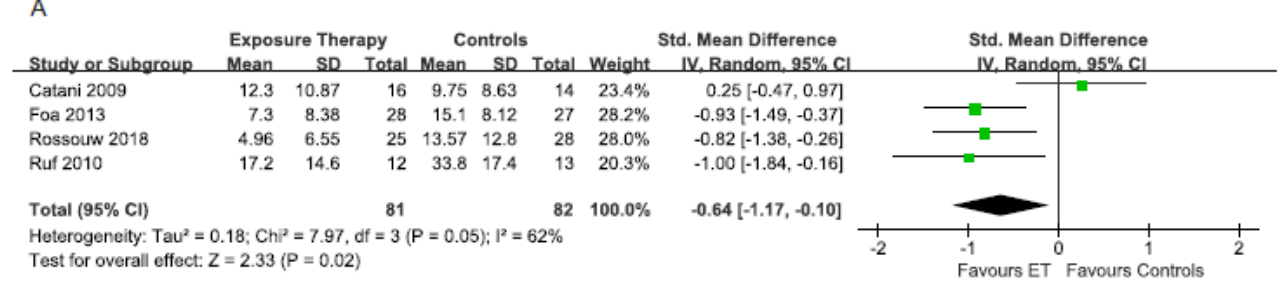

B

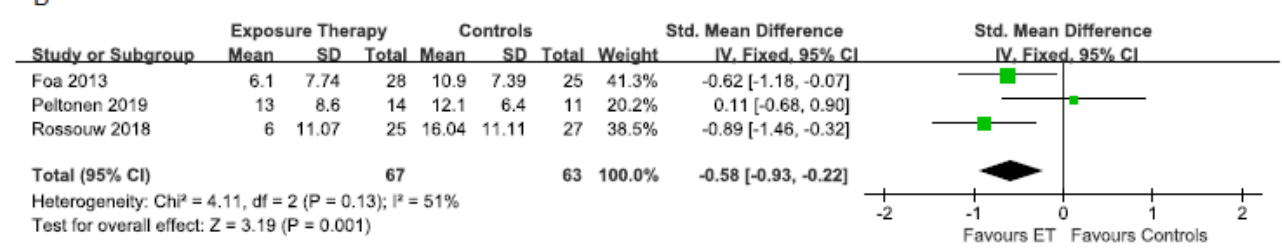

C

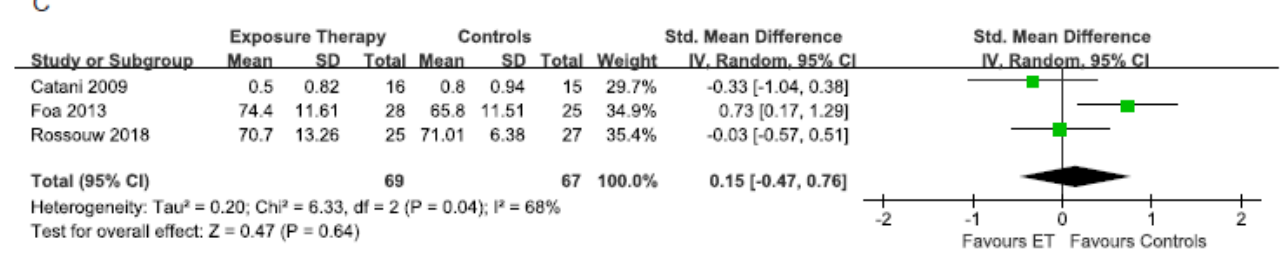

\section{Figure 3}

The efficacy of exposure therapy at 1-12 months follow-up (A), the effect of exposure therapy on depressive symptoms (B), and the effects of exposure therapy on quality of life/social functioning (C).

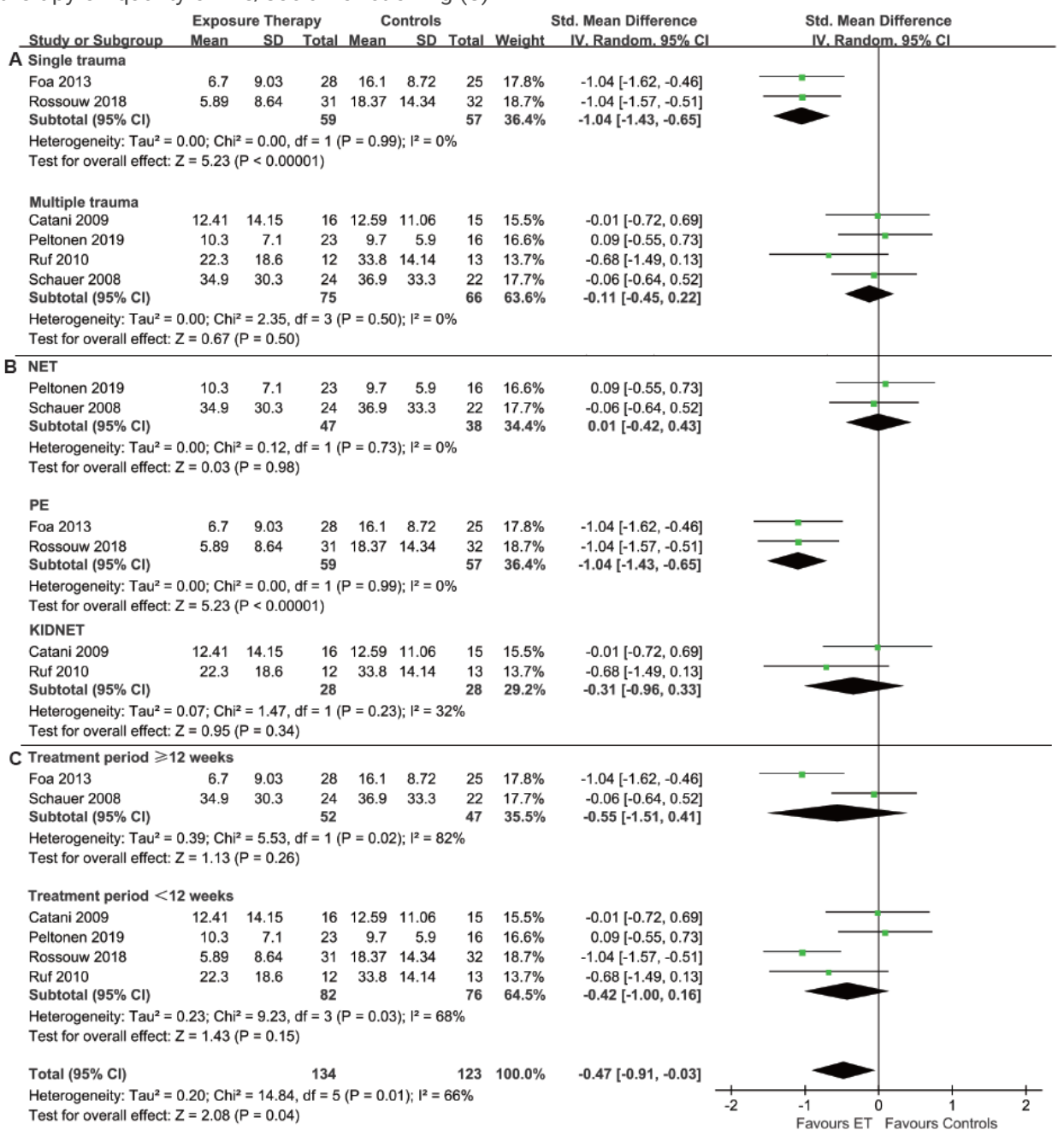


Figure 4

The subgroup analysis of the efficacy at post-treatment.

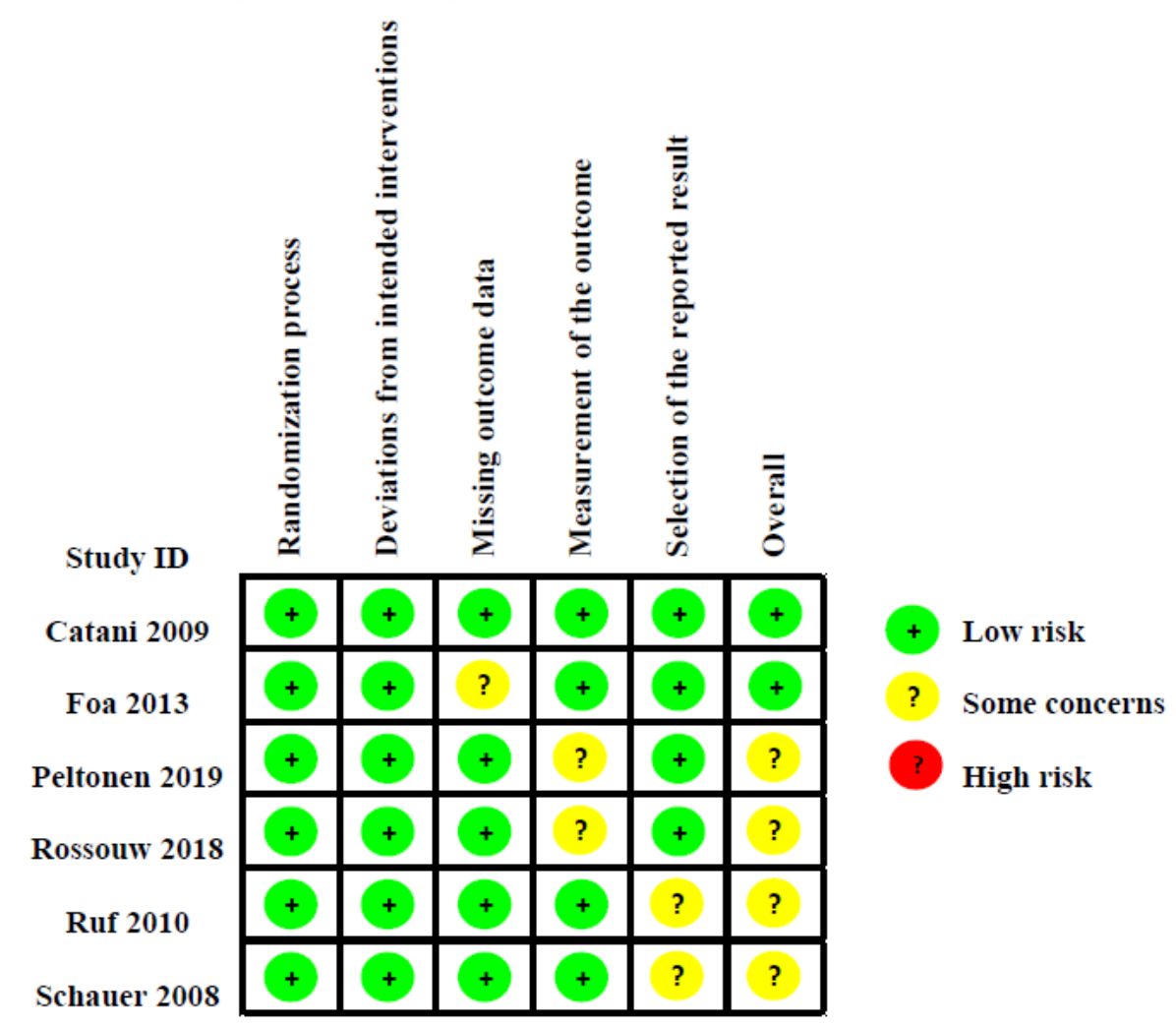

Figure 5

Risk of bias graph: review authors' judgements about each risk of bias item presented as percentages across all included studies. 